\title{
Article
}

\section{The thermal decomposition of natural mixtures of huntite and hydromagnesite}

\author{
Hollingbery, L.A. and Hull, T Richard \\ Available at http://clok.uclan.ac.uk/3414/ \\ Hollingbery, L.A. and Hull, T Richard ORCID: 0000-0002-7970-4208 (2012) The \\ thermal decomposition of natural mixtures of huntite and hydromagnesite. \\ Thermochimica Acta, 528 . pp. 45-52. ISSN 00406031
}

It is advisable to refer to the publisher's version if you intend to cite from the work. http://dx.doi.org/10.1016/j.tca.2011.11.002

For more information about UCLan's research in this area go to http://www.uclan.ac.uk/researchgroups/ and search for < name of research Group>.

For information about Research generally at UCLan please go to http://www.uclan.ac.uk/research/

All outputs in CLoK are protected by Intellectual Property Rights law, including Copyright law. Copyright, IPR and Moral Rights for the works on this site are retained by the individual authors and/or other copyright owners. Terms and conditions for use of this material are defined in the policies page.

\section{CLoK}

Central Lancashire online Knowledge www.clok.uclan.ac.uk

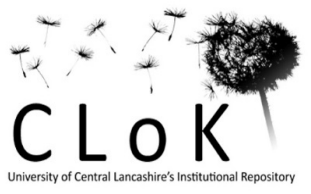




\section{The Thermal Decomposition of Natural Mixtures of Huntite and Hydromagnesite.}

L.A.Hollingbery ${ }^{a, b^{\star}}$, T.R.Hull

${ }^{a}$ Minelco Ltd, Raynesway, Derby, DE21 7BE. Luke.Hollingbery@Minelco.com.

${ }^{\mathrm{b}}$ School of Forensic and Investigative Sciences, University of Central Lancashire, Preston, PR1 2HE

Keywords: hydromagnesite, huntite, fire, flame, retardant, filler

\section{Abstract}

The thermal decomposition of natural mixtures of huntite and hydromagnesite has been investigated. Hydromagnesite decomposes endothermically giving off water and carbon dioxide, the mechanism is dependent on heating rate. Mass losses measured by TGA are consistent with the loss of four water molecules, from the loss of water of crystallisation, and one water molecule from the decomposition of the hydroxide ion, followed by the loss of four carbon dioxide molecules from the decomposition of the carbonate ions. The magnesium carbonate, remaining after the dehydration of hydromagnesite, recrystallises exothermically in response to higher heating rates. This causes the decomposition of the carbonate ions to split into two stages with the second stage moving to a higher temperature. The magnitude of each stage is dependent on the heating rate. Huntite decomposes endothermically, at a higher temperature, giving off carbon dioxide in two stages. Mass losses measured by TGA are consistent with the loss of three carbon dioxide molecules, from the decomposition the carbonate ions associated with the three magnesium ions, followed by the loss of a single carbon dioxide molecule associated with the decomposition of the carbonate ion associated with the calcium ion.

\section{Introduction}

Mixtures of huntite and hydromagnesite form naturally and are mined, processed and sold commercially as an alternative to the commonly used mineral filler fire retardants, aluminium hydroxide (ATH) and magnesium hydroxide (MDH). Previous authors have discussed the decomposition of huntite[1-6] and hydromagnesite[1,3,7-19]. A recent comprehensive review[1] has drawn together the present state of knowledge relating to the thermal decomposition of these minerals from various natural sources, both as mixtures and as individual minerals. It also highlights comparisons with synthetic forms of these minerals. Little, if anything, has been reported on the huntite and hydromagnesite from the World's largest known deposits in Turkey. This deposit is operated commercially and the minerals are sold as a fire retardant additive, by Minelco, under the tradename 'UltraCarb'. Huntite and hydromagnesite from this deposit are the focus of the work discussed within this paper.

Hydromagnesite has the following chemical formula[20] and thermally decomposes releasing water and carbon dioxide, leaving a solid residue of magnesium oxide.

$$
\mathrm{Mg}_{5}\left(\mathrm{CO}_{3}\right)_{4}(\mathrm{OH})_{2} \cdot 4 \mathrm{H}_{2} \mathrm{O} \rightarrow 5 \mathrm{MgO}+4 \mathrm{CO}_{2}+5 \mathrm{H}_{2} \mathrm{O}
$$

Huntite has the following chemical formula[21] and thermally decomposes releasing carbon dioxide, leaving a solid residue of magnesium oxide and calcium oxide. 


$$
\mathrm{Mg}_{3} \mathrm{Ca}\left(\mathrm{CO}_{3}\right)_{4} \rightarrow 3 \mathrm{MgO}+\mathrm{CaO}+4 \mathrm{CO}_{2}
$$

The thermal degradation of these minerals through endothermic release of carbon dioxide and water has lead to several studies showing the application of mixtures of these minerals including fire retardant polymer compounds[22-42], controlling burning rates in cigarettes[43,44], and as a potential material for fighting forest fires[45-49].

\section{Experimental}

\subsection{Materials}

Huntite and hydromagnesite

Samples of huntite and hydromagnesite were supplied by Minelco Ltd. The minerals were mined from the deposit of mixed huntite and hydromagnesite in Turkey. The mineral samples supplied had been processed into powder form suitable for incorporation as a fire retardant into polymer compounds. Various ratios of the minerals were supplied ranging from almost pure huntite to almost pure hydromagnesite. Because the minerals in the Turkish deposits naturally formed as mixtures it is very difficult to find $100 \%$ pure samples of either mineral.

\section{Synthetic hydromagnesite}

Synthetic hydromagnesite was obtained from Solvay under the tradename Carbomag TL. The chemical formula quoted by Solvay for Carbomag TL $\left(4 \mathrm{MgCO}_{3} \cdot \mathrm{Mg}[\mathrm{OH}]_{2} \cdot 4 \mathrm{H}_{2} \mathrm{O}\right)$ is identical to natural hydromagnesite. This material provides a reference point for discussion since it is synthetically produced and of high purity.

Magnesium carbonate, calcium carbonate, and magnesium hydroxide

Also used for comparison and discussion purposes were magnesium carbonate, calcium carbonate and magnesium hydroxide. Magnesium carbonate and calcium carbonate were from natural sources and supplied by Minelco Ltd. under the trade names HyperCarb 5 and MicroCarb ST10H. Magnesium hydroxide was obtained from Martinswerk under the tradename Magnifin H5A.

\subsection{Test methods}

\section{Thermogravimetric Analysis (TGA)}

TGA tests were carried out using a TA Instruments Q5000IR. Unless otherwise stated testing was carried out in air at a heating rate of $10^{\circ} \mathrm{Cmin}^{-1}$.

\section{Simultaneous Thermogravimetric Analysis with Fourier Transform Infrared Analysis (STA-FTIR)}

The equipment used for this work was an STA 780 coupled with a Nicolet Magna IR Spectrometer 550. Samples of approximately $10 \mathrm{mg}$ were heated at a controlled heating rate of $10^{\circ} \mathrm{Cmin}^{-1}$ in air from room temperature up to $1000^{\circ} \mathrm{C}$ using the TGA instrument. The evolved gases were fed to the FTIR analyser allowing analysis of the gases to be associated with mass losses measured by TGA.

\section{Differential Scanning Calorimetry (DSC)}

DSC analysis was carried out using a Rheometric Scientific DSC-1500. Samples were heated in a nitrogen atmosphere at a heating rate of $10^{\circ} \mathrm{Cmin}^{-1}$ unless otherwise stated. 


\section{Results and Discussion}

\subsection{Thermal decomposition of huntite and hydromagnesite}

Both huntite and hydromagnesite thermally decompose, losing mass and giving off water and carbon dioxide. Figure 1 shows a comparison of the thermal decomposition of the two minerals with a commercially available mixture of huntite and hydromagnesite (UltraCarb LH15).

Huntite decomposes through two stages. The first stage occurs between about $400^{\circ} \mathrm{C}$ and $630^{\circ} \mathrm{C}$ with an associated loss in mass of $38 \%$, and the second stage occurs between about $630^{\circ} \mathrm{C}$ and $750^{\circ} \mathrm{C}$ with a further mass loss of $12 \%$ making a total mass loss of $50 \%$. Huntite has a total molecular mass of $353 \mathrm{gmol}^{-1}$. Since it is a carbonate mineral it is likely that its thermal decomposition consists of release of carbon dioxide, which has a molecular mass of $44 \mathrm{gmol}^{-1}$. Release of three carbon dioxide molecules followed by further release of one carbon dioxide molecule gives calculated mass losses of $37.4 \%$ and $12.5 \%$, which is in very close agreement with the measured values.

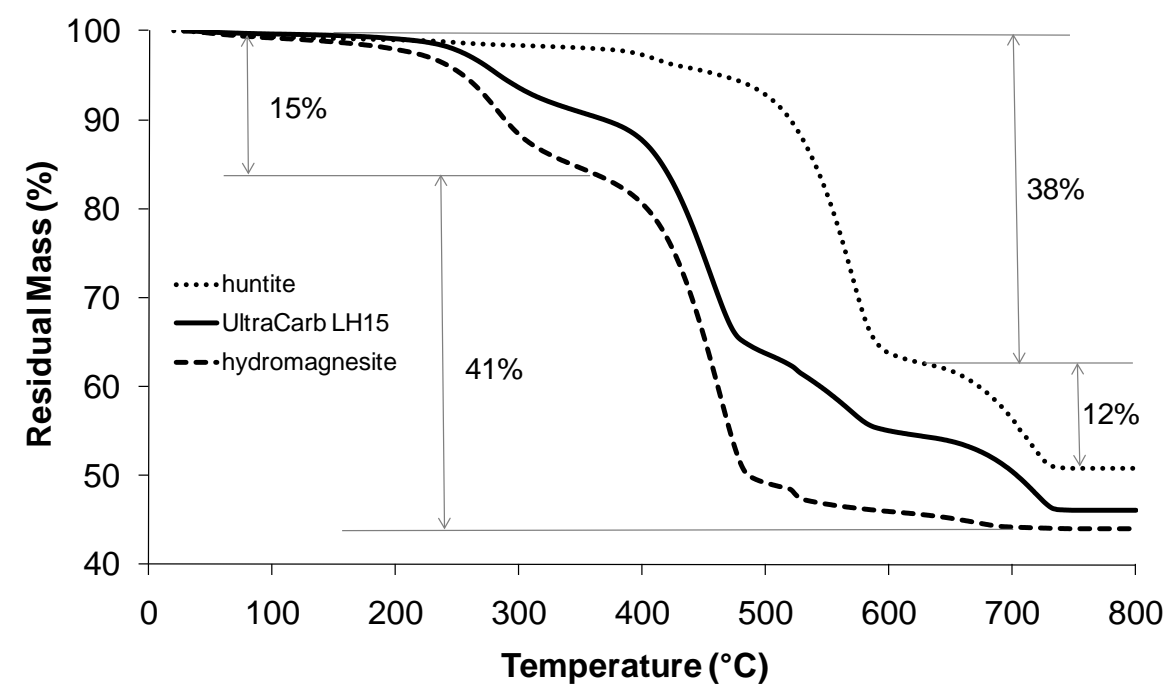

Figure 1: Thermal decomposition, measured by TGA, of huntite, hydromagnesite, and a commercially available mixture

The decomposition of hydromagnesite is more complicated than huntite. There is a mass loss of $15 \%$ up to about $350^{\circ} \mathrm{C}$ and a further loss of $41 \%$ by about $700^{\circ} \mathrm{C}$. Using hydromagnesite's molecular mass of $467.5 \mathrm{gmol}^{-1}$ it can be calculated that loss of the four water molecules (from water of crystallisation) would account for a mass loss of $15.40 \%$. The loss of a further water molecule from the decomposition of the hydroxide ion and loss of four carbon dioxide molecules would account for a further $41.50 \%$ (3.85\% and $37.65 \%$ respectively) mass loss. The figures are close to the measured values, and suggest that the decomposition of the hydroxide ion overlaps the decomposition of the carbonate ions. It is also clear from Figure 1 that the decomposition is not a simple two step mechanism; this will be discussed in more detail later. 
The mass loss profile for the natural mixture of huntite and hydromagnesite shows a four step mechanism, which is a combination of the two individual minerals and provides thermal activity over a wide temperature range.

Figure 2 shows the thermal decomposition of a commercially available mixture of huntite and hydromagnesite (UltraCarb LH15) measured by DSC. It is clear that the major decompositions of the minerals are all endothermic, meaning that these minerals have great potential as fire retardants. By comparison with Figure 1 it is also clear that each of the decompositions measured by TGA is associated with an endotherm. The total heat of decomposition of the mixture of huntite and hydromagnesite is approximately $-990 \mathrm{Jg}^{-1}$. The peak heights will vary depending on the ratio of the two minerals.

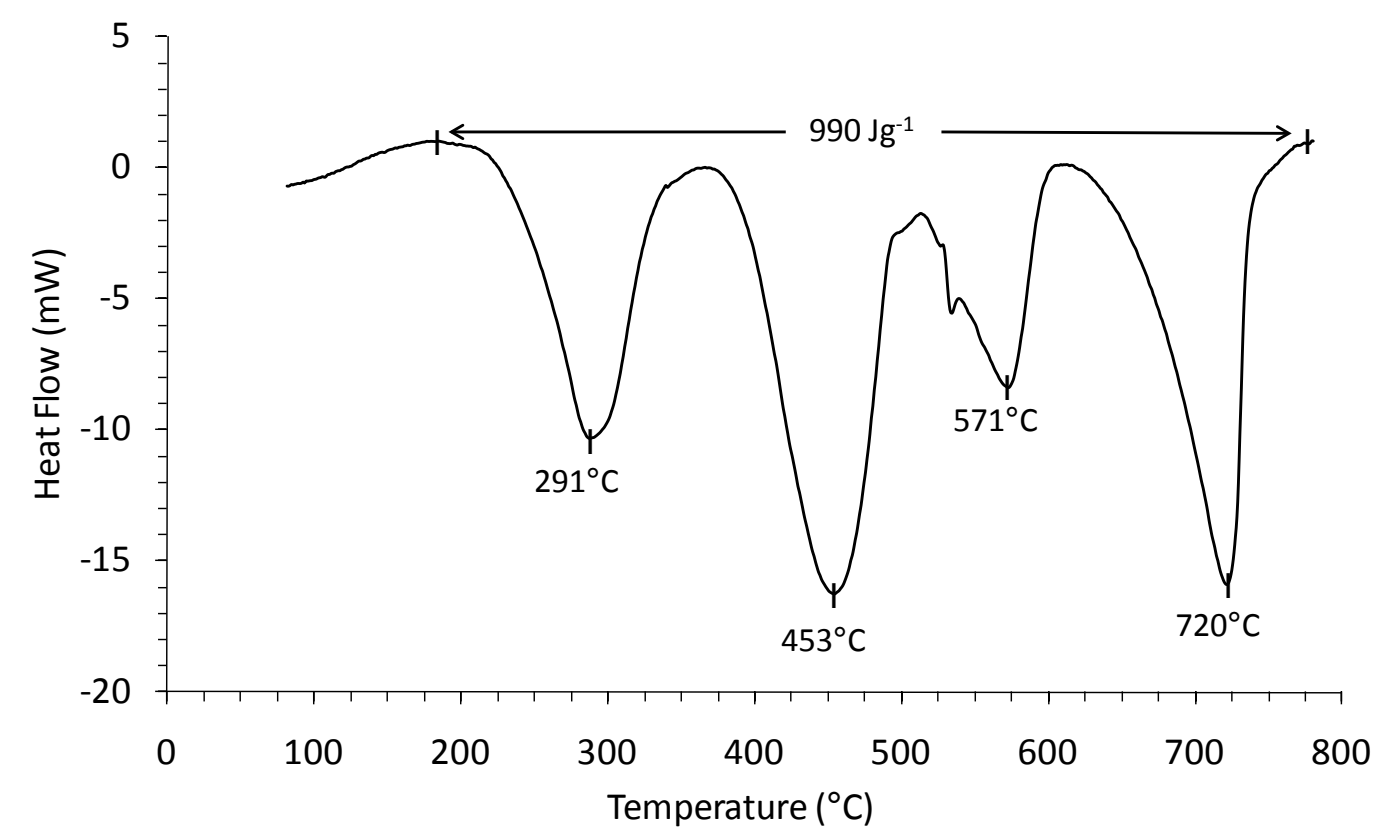

Figure 2: Thermal decomposition, measured by DSC, of a commercial mixture of huntite and hydromagnesite

\subsection{Thermal decomposition and investigation of huntite's chemical formulae}

Ozao et. al.[6] used the fact that the chemical formula for huntite, $\mathrm{Mg}_{3} \mathrm{Ca}\left(\mathrm{CO}_{3}\right)_{4}$, can also be written as, $3 \mathrm{MgCO}_{3} \cdot \mathrm{CaCO}_{3}$, to show by DTA that mechanical mixtures of calcium carbonate and magnesium carbonate have similar although not identical thermal decomposition characteristics as huntite. That the thermal decomposition is not identical is not surprising since huntite forms its own distinct crystal structure[50]. In a similar way the current sample of Turkish huntite has been compared to calcium carbonate and magnesium carbonate using TGA (Figure 3). 


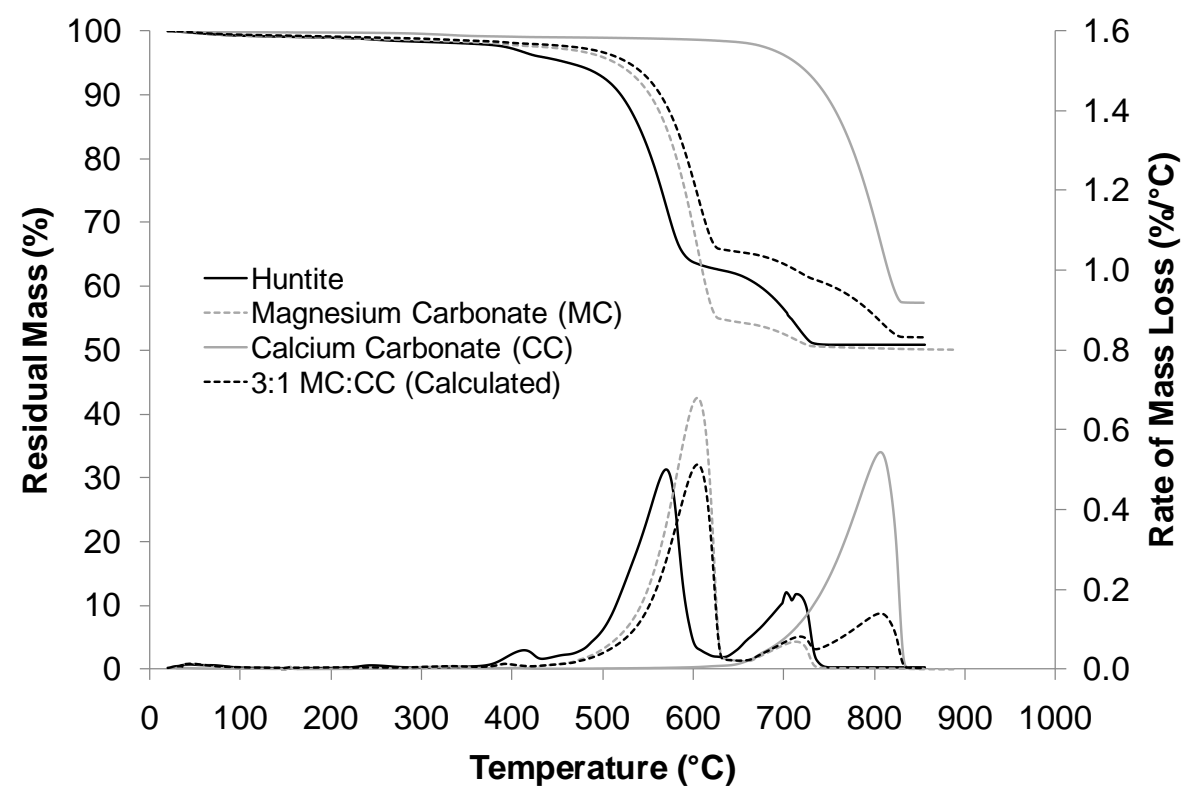

Figure 3: Comparison of huntite with magnesium carbonate and calcium carbonate using TGA

By proportionally summing the mass loss profiles of magnesium carbonate and calcium carbonate in a 3:1 ratio (the same ratio as present in huntite) a calculated mass loss profile has been constructed. This calculated mass loss profile is similar to that of huntite. The mass losses from magnesium carbonate and calcium carbonate in the calculated profile correspond well with those of the first and second stages of mass loss from huntite. The mass losses occur at lower temperatures in huntite than in the calculated profile. This is because huntite is not a mechanical mixture of two individual minerals with their own crystalline structures. It is a single mineral with a single crystalline structure that happens to contain the same ratio of magnesium and calcium atoms, and carbonate ions as a mechanical mixture of magnesium carbonate and calcium carbonate. This indicates that the decomposition mechanism of huntite is as follows:

$1^{\text {st }}$ stage - between 400 and $630^{\circ} \mathrm{C}$, decomposition of the carbonate ions associated with the magnesium atoms, releasing carbon dioxide and leaving a magnesium oxide calcium carbonate residue.

$\mathrm{Mg}_{3} \mathrm{Ca}\left(\mathrm{CO}_{3}\right)_{4} \rightarrow 3 \mathrm{MgO} . \mathrm{CaCO}_{3}+3 \mathrm{CO}_{2}$

Clearly the calcium carbonate does not form the same crystal structure as natural calcium carbonate because it decomposes at a lower temperature. This is due to the presence of the magnesium oxide within the structure.

$2^{\text {nd }}$ stage - between 630 and $750^{\circ} \mathrm{C}$, decomposition of the remaining carbonate ions associated with the calcium atoms, releasing carbon dioxide and leaving a mixed residue of magnesium oxide and calcium oxide.

$3 \mathrm{MgO} . \mathrm{CaCO}_{3} \rightarrow 3 \mathrm{MgO} . \mathrm{CaO}+\mathrm{CO}_{2}$

\subsection{Thermal decomposition and investigation of hydromagnesite's chemical formulae}

A similar analysis to the comparison of huntite with mixtures of calcium carbonate and magnesium carbonate can be carried out with hydromagnesite. The chemical formula of hydromagnesite, $\mathrm{Mg}_{5}\left(\mathrm{CO}_{3}\right)_{4}(\mathrm{OH})_{2} \cdot 4 \mathrm{H}_{2} \mathrm{O}$, can also be written as, $4 \mathrm{MgCO}_{3} \cdot \mathrm{Mg}(\mathrm{OH})_{2} \cdot 4 \mathrm{H}_{2} \mathrm{O}$. Therefore, comparison with magnesium carbonate and magnesium hydroxide in a 4:1 ratio (Figure 4) provides some insight into 
its thermal decomposition. The analysis is not as straightforward as with huntite since hydromagnesite contains four molecules of water of crystallisation which are not present in either magnesium hydroxide or magnesium carbonate.

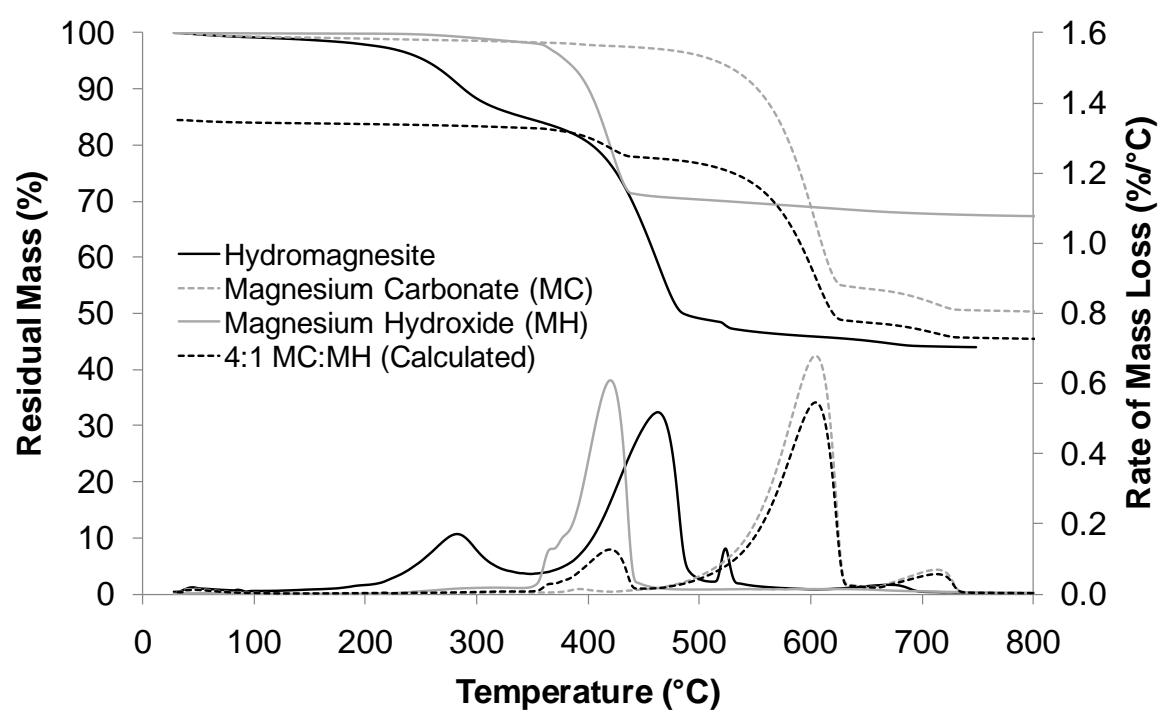

Figure 4: Comparison of hydromagnesite with magnesium carbonate and magnesium hydroxide using TGA

It has been shown[7-9,11,15-19] that hydromagnesite thermally decomposes by first losing water of crystallisation, followed by decomposition of the hydroxide ion and finally release of carbon dioxide from decomposition of the carbonate ion. Calculation using atomic masses shows that these three decompositions would result in mass losses of $15.45 \%, 3.86 \%$, and $37.77 \%$ respectively and result in a total mass loss of $57.08 \%$.

The decomposition of Turkish hydromagnesite, shown in Figure 4, does not clearly separate the three decomposition steps. However, it was shown in Figure 1 that at $350^{\circ} \mathrm{C}$ (the shoulder between the two major mass losses) the mass loss is $15 \%$, a further mass loss of $41 \%$ occurred by $700^{\circ} \mathrm{C}$, giving a total mass loss of $56 \%$. This is very close to the expected total mass loss of $57.08 \%$. The mass loss associated with the decomposition of the hydroxide ion probably occurs somewhere between $330^{\circ} \mathrm{C}$ and $430^{\circ} \mathrm{C}$ but is overshadowed by the larger mass loss associated with the decomposition of the carbonate ions. This temperature range is also close to the temperature range over which the hydroxide ion in magnesium hydroxide decomposes.

The decomposition profiles of magnesium carbonate and magnesium hydroxide were summed together in a 4:1 ratio. The four water molecules present in hydromagnesite accounting for $15.45 \%$ of the mass have been taken into account in the calculation, therefore the line in Figure 4 starts with a total residual mass of $84.55 \%$. As expected from the mass loss profiles of magnesium carbonate and magnesium hydroxide, the sum of the two components does not fit closely with that of hydromagnesite in terms of decomposition temperatures. As discussed above, the decomposition temperature of the magnesium hydroxide does appear to coincide quite closely with that of the hydroxide ion in hydromagnesite. However, the decomposition temperature of magnesium carbonate does not coincide with that of the carbonate ion in hydromagnesite, although the total mass losses do closely agree. Although the chemical composition of hydromagnesite is similar to a 4:1 mixture of magnesium carbonate and magnesium hydroxide the crystal structure of hydromagnesite [51-53] is quite different leading to a more complex decomposition that predicted from simple mixtures. 
Comparison of natural hydromagnesite with synthetic hydromagnesite (Figure 5) shows that the mass losses of the two materials are almost identical, as would be expected. However, the synthetic hydromagnesite decomposes at a lower temperature than the natural material.

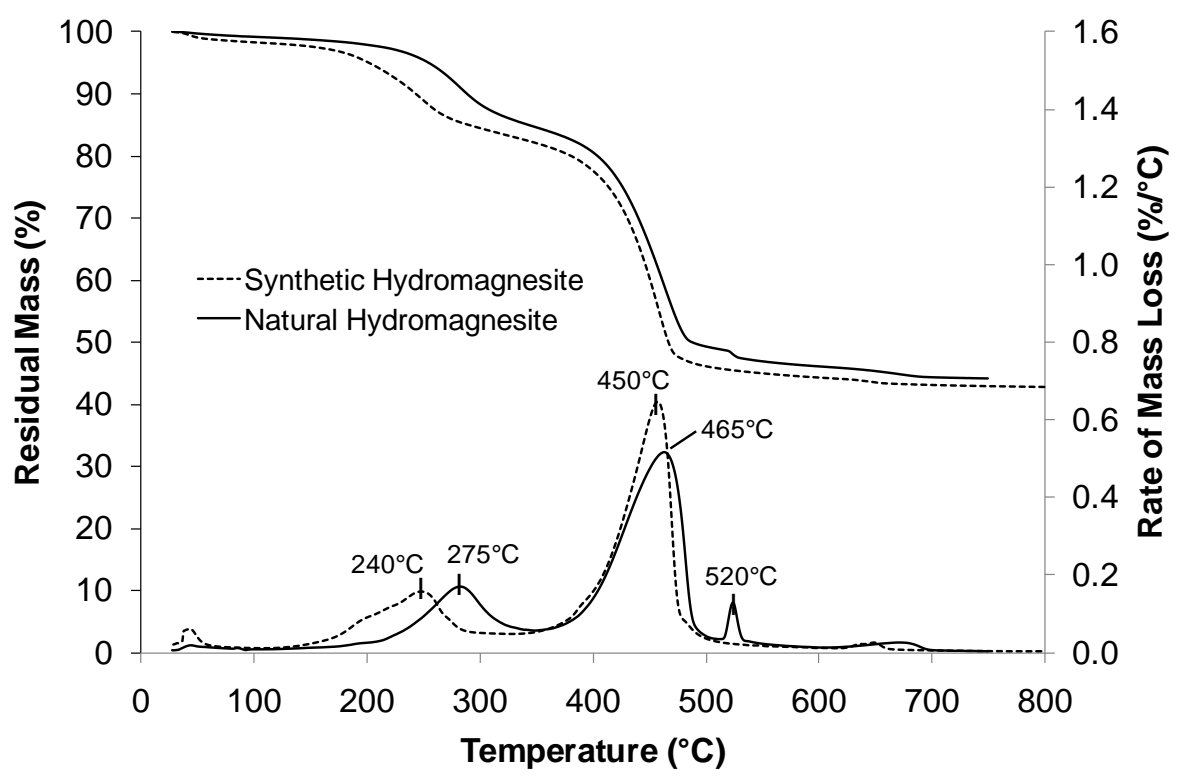

Figure 5: Comparison of natural hydromagnesite with synthetic hydromagnesite using TGA

The maximum rate of mass loss associated with loss of water of crystallisation occurs at about $275^{\circ} \mathrm{C}$ for natural hydromagnesite and at about $240^{\circ} \mathrm{C}$ for the synthetic material. The onset of decomposition is also much lower (well below $200^{\circ} \mathrm{C}$ ) for the synthetic material. This is a significant advantage in favour of the natural material in terms of processing in polymer compounds. The lower onset of decomposition of the synthetic material restricts its use to polymers that are processed below that temperature.

The maximum rate of decomposition associated with the decomposition of the carbonate ions occurs at about $465^{\circ} \mathrm{C}$ for the natural hydromagnesite and at about $450^{\circ} \mathrm{C}$ for the synthetic hydromagnesite. Again the decomposition is occurring at a lower temperature in the synthetic material although in this case the difference is smaller and not significant in terms of processing polymers filled with hydromagnesite because it is well above the processing temperature of most polymers.

The additional peak of mass loss at $520^{\circ} \mathrm{C}$ measured in the natural hydromagnesite but not present in the synthetic hydromagnesite is due to crystallisation of magnesium carbonate during decomposition of the mineral. This will be discussed in more detail below.

From these results it is clear that the decomposition of synthetic hydromagnesite follows a similar pathway to that of natural hydromagnesite albeit at slightly lower temperatures. This difference in decomposition temperatures is probably due to variations in the crystal structure between the natural and synthetic materials. It has been reported[54] that the degree of crystallinity of synthetic hydromagnesite is lower than that found in naturally formed material. This has been attributed to differences in the formation conditions such as temperatures and time scales.

According to the technical datasheet for the synthetic hydromagnesite, supplied by Solvay, the average particle size $\left(d_{50}\right)$ is $0.7 \mu \mathrm{m}$ and the BET surface area is $22 \mathrm{~m}^{2} \mathrm{~g}^{-1}$. This compares to a $d_{50}$ of $4.9 \mu \mathrm{m}$ and a BET surface area of $9.7 \mathrm{~m}^{2} \mathrm{~g}^{-1}$ for the natural hydromagnesite. This difference in morphology may also account for part of the difference in the decomposition temperatures. 


\subsection{Analysis of decomposition gases}

In order to further investigate the decomposition mechanism of huntite and hydromagnesite, the decomposition gases generated during TGA analysis were identified using FTIR. This was done in real time allowing the gases indentified to be linked to a specific mass loss and temperature range. Figure 6 shows the Gram-Schmidt data from FTIR analysis of the evolved gases from huntite. This shows the output of the FTIR detector without linking it to a wavenumber and therefore shows the temperature ranges where evolved gases are detected without identifying them. Unsurprisingly gases are detected in relation to the two mass losses measured by TGA. There is a slight offset between the temperatures of maximum mass loss rate and temperatures where maximum FTIR peak intensities are measured due to a progressively increasing delay as the evolved gases pass through the FTIR gas cell.

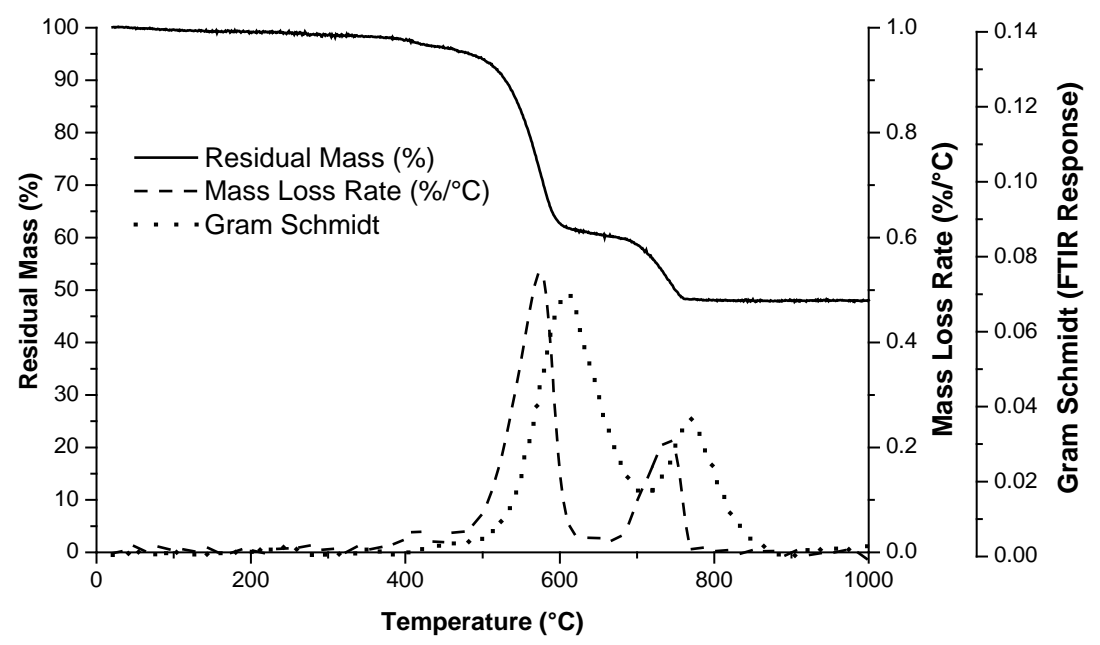

Figure 6: Gram Schmidt data from TGA-FTIR analysis of huntite

Figure 7 shows the FTIR spectra of the evolved gases measured at temperatures determined by the maxima and minima in the Gram Schmidt data. The FTIR peaks that can be seen between 2400 and $2200 \mathrm{~cm}^{-1}$ and below $750 \mathrm{~cm}^{-1}$ are characteristic of carbon dioxide. This confirms that the two mass losses measured during the decomposition of huntite are solely due to the decomposition of the carbonate ions and the subsequent release of carbon dioxide. 
$900^{\circ} \mathrm{C}$

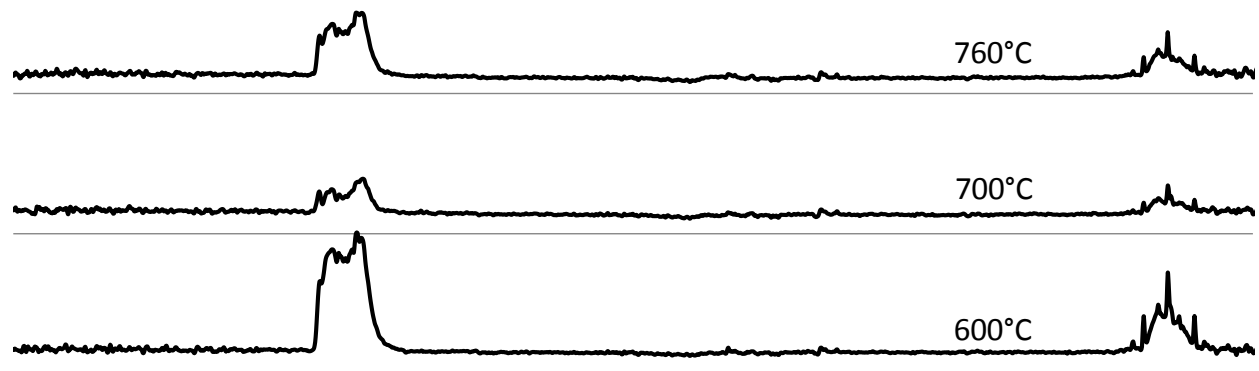

$300^{\circ} \mathrm{C}$

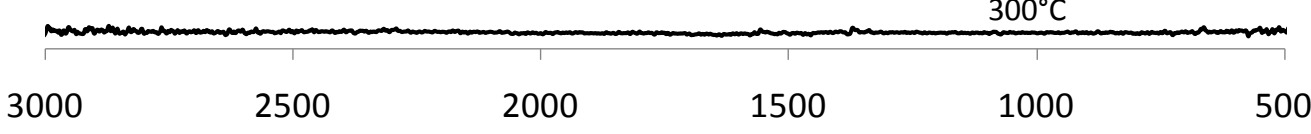

Wavenumber $\left(\mathrm{cm}^{-1}\right)$

Figure 7: FTIR spectra of gases evolved during decomposition of huntite

Figure 8 shows the mass loss and Gram Schmidt data for the thermal decomposition of hydromagnesite. As with the huntite data, the maxima and minima in this data has been used to select the temperatures for FTIR analysis of the evolved gases.

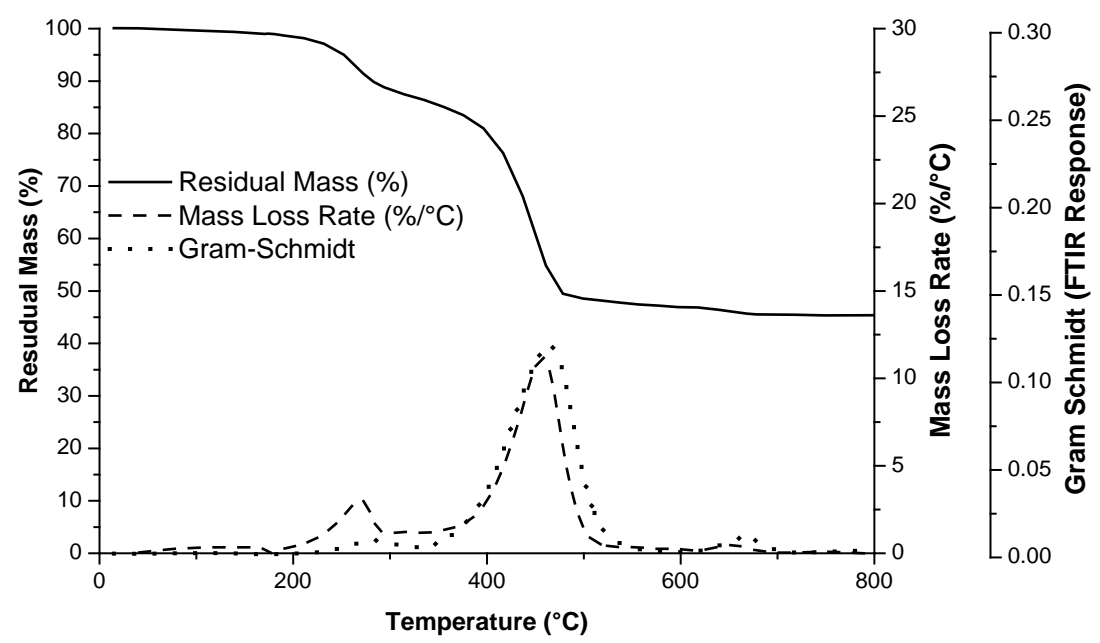

Figure 8: Gram Schmidt data from TGA-FTIR analysis of hydromagnesite

The FTIR spectra of the gases evolved during the decomposition of hydromagnesite are shown in Figure 9. The broad FTIR peaks measured below $350^{\circ} \mathrm{C}$ at wavenumbers between 2000 and $1200 \mathrm{~cm}^{-1}$ are characteristic of water. Above $350^{\circ} \mathrm{C}$ no further water was detected, this confirms that the initial mass loss from hydromagnesite is due to the release of the crystalline water and decomposition of the hydroxide ion. Above $350^{\circ} \mathrm{C}$ the FTIR spectra are characteristic of carbon dioxide due to decomposition of the carbonate ions. 


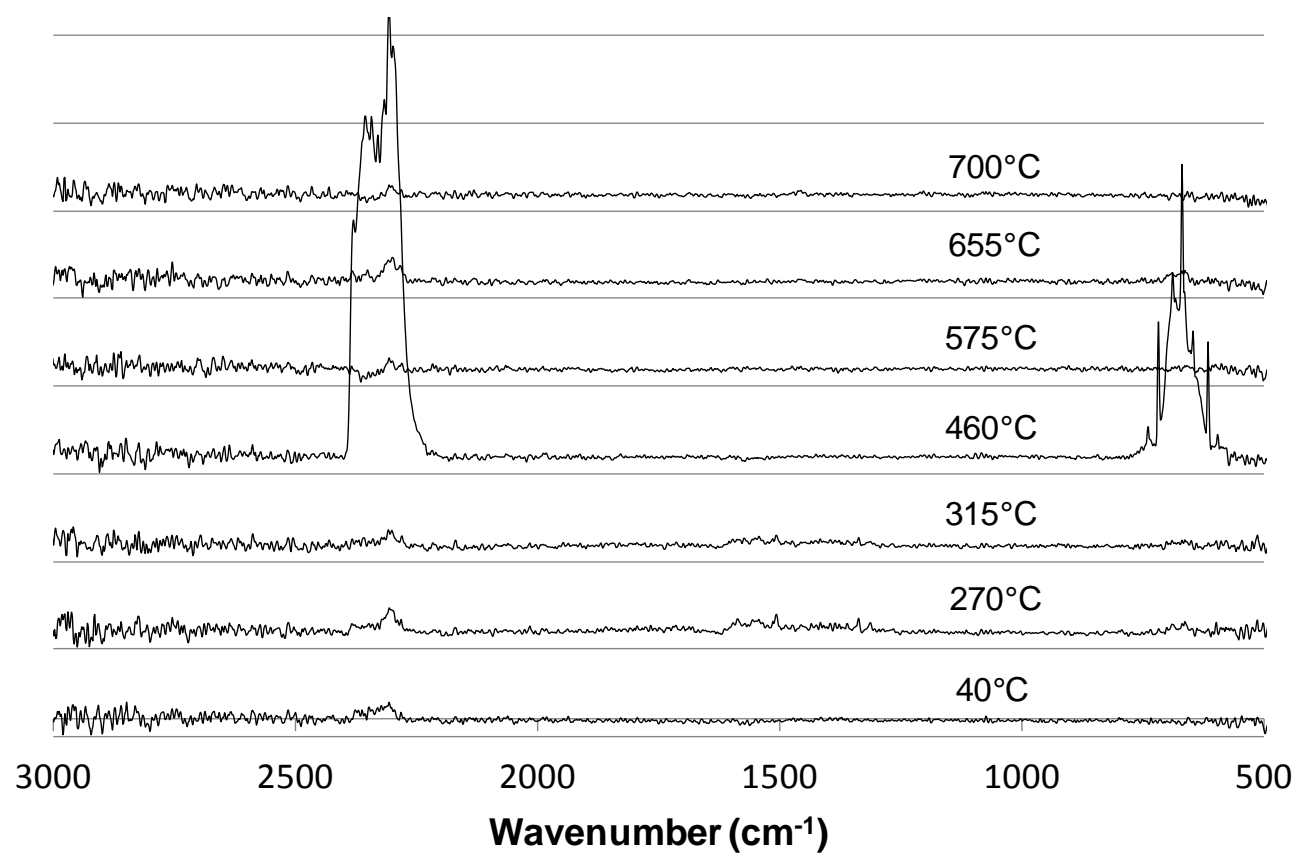

Figure 9: FTIR spectra of gases evolved during the decomposition of hydromagnesite

To further clarify, the variation in magnitude of the peaks with temperature at $1308 \mathrm{~cm}^{-1}$ and $2310 \mathrm{~cm}^{-1}$ (which correspond to the areas associated with water and carbon dioxide respectively) have been plotted and shown in Figure 10. This breaks the Gram Schmidt data down into its components clearly demonstrating that the first mass loss from hydromagnesite is due to loss of water and the second mass loss is due to loss of carbon dioxide. The presence of water vapour and traces of carbon dioxide within the FTIR spectrophotometer give rise to the noisy baseline.

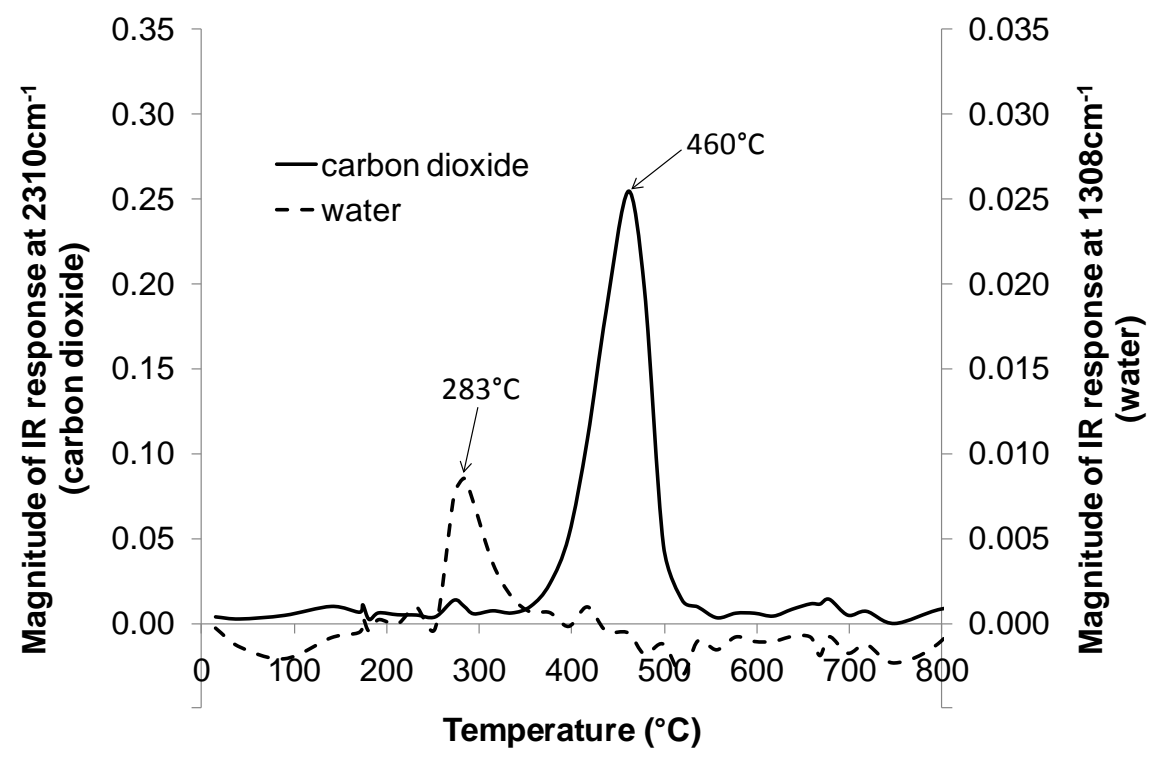

Figure 10: Analysis of gases evolved during decomposition of hydromagnesite 


\subsection{Effect of heating rate on the thermal decomposition of hydromagnesite}

The rate of heating has a significant effect on the decomposition of hydromagnesite. Figure 11 shows how heating rate affects the mass loss profile of hydromagnesite. At a heating rate of $1^{\circ} \mathrm{Cmin}^{-1}$ there are two clearly defined mass losses with peak mass loss rates at $240^{\circ} \mathrm{C}$ and $405^{\circ} \mathrm{C}$, these are due to the evolution of water and carbon dioxide respectively. Increasing the heating rate to $10^{\circ} \mathrm{Cmin}^{-1}$ moves these peaks about $280^{\circ} \mathrm{C}$ and $455^{\circ} \mathrm{C}$ and broadens the mass loss rate peaks. This is a simple heat transfer effect, at $1^{\circ} \mathrm{Cmin}^{-1}$ the sample temperature will closely match that of the furnace temperature, at higher heating rates the sample temperature will lag behind the furnace temperature causing the rate of mass loss peaks to move to apparently higher temperatures and also making the peaks less sharp.

Above $450^{\circ} \mathrm{C}$ more complex differences become apparent. At a heating rate of $1^{\circ} \mathrm{Cmin}^{-1}$ the mass loss rate has returned to almost zero by $450^{\circ} \mathrm{C}$, at a heating rate of $10^{\circ} \mathrm{Cmin}^{-1}$ the mass loss rate returns to almost zero at about $500^{\circ} \mathrm{C}$, but is then followed by another small peak in mass loss rate at $520^{\circ} \mathrm{C}$. As the rate of heating is increased further the additional mass loss at $520^{\circ} \mathrm{C}$ increases and is compensated for by a reduction in mass loss between 400 and $500^{\circ} \mathrm{C}$. This is showing a clear change in the decomposition mechanism of the carbonate ions. A higher heating rate causes the single stage decomposition to split into two stages.

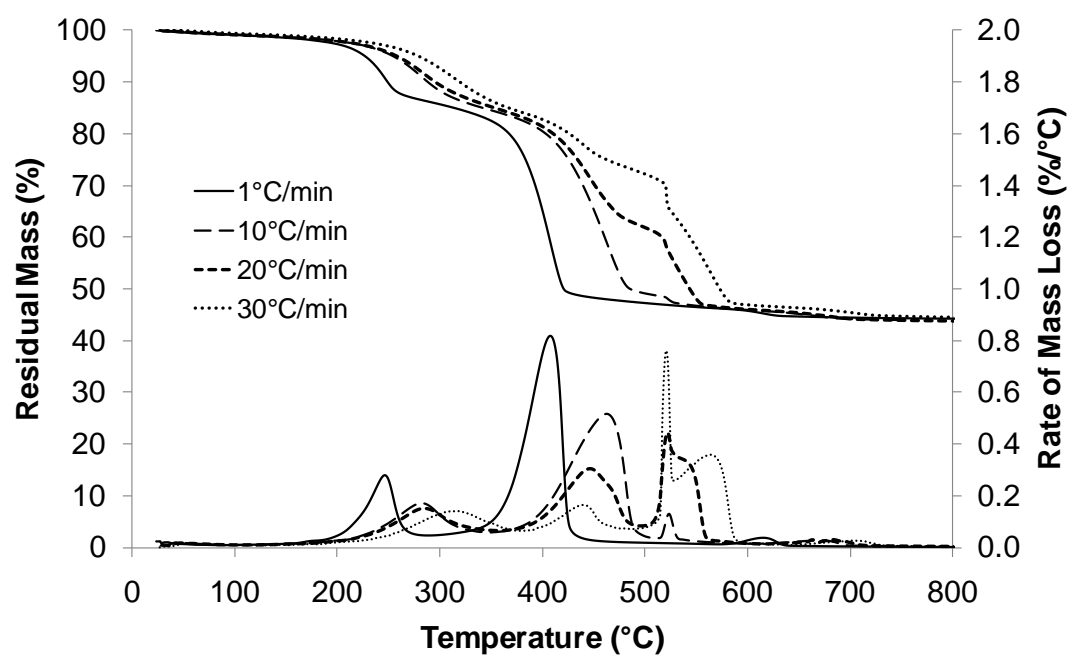

Figure 11: Effect of heating rate on the thermal decomposition of hydromagnesite measured by TGA

As the heating rate increases, the release of water apparently moves to a higher temperature due to heat transfer effects. At $30^{\circ} \mathrm{Cmin}^{-1}$ the release of water is spread over a much wider temperature range than at lower heating rates and the peak rate of water release occurs at a higher temperature. In addition to heat transfer effects as the heating rate increases, the water molecules released within the hydromagnesite particles have less time to diffuse to the surface further spreading the apparent temperature range over which the release occurs. The carbon dioxide release splits into two stages as the heating rate is increased. The release of carbon dioxide initiates at about the same temperature, just less than $400^{\circ} \mathrm{C}$, for heating rates between 10 and $30^{\circ} \mathrm{Cmin}^{-1}$, however less mass is lost and the peak rate of mass loss moves to a lower temperature. At $520^{\circ} \mathrm{C}$ a sudden mass loss occurs which increases with heating rate. This mass loss is associated with an exotherm (Figure 12) at $520^{\circ} \mathrm{C}$ followed by an endotherm which both increase with heating rate. 


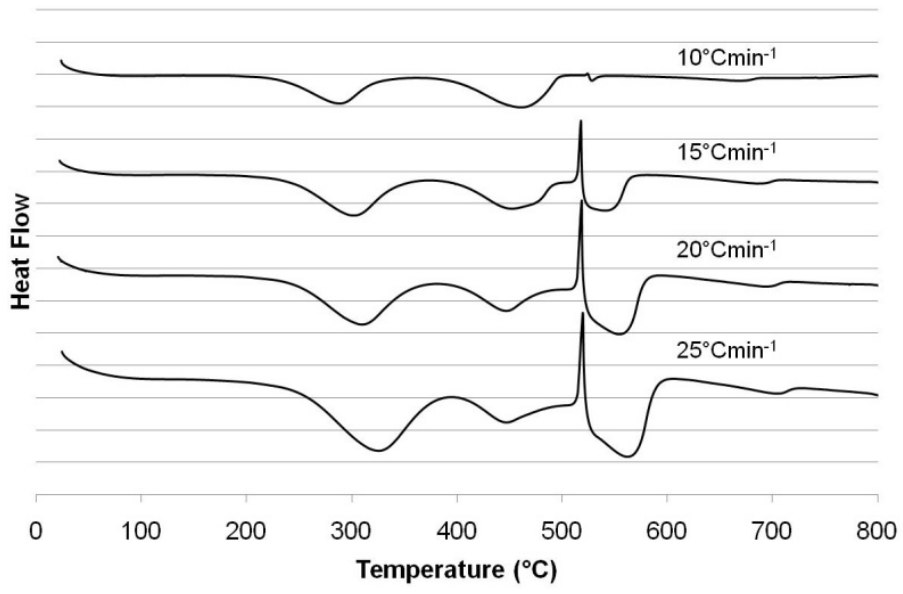

Figure 12: Effect of heating rate on the thermal decomposition of hydromagnesite measured by DSC

This affect of heating rate on the decomposition of hydromagnesite has been reported by several authors[11-13,15-19]. The partial pressure of carbon dioxide has been shown[13,16] to have a strong influence on the second stage of carbonate decomposition and associated exotherm. It has also been shown $[11,13,19]$ that the exotherm is due to the formation of crystalline magnesium carbonate after the initial loss of some carbon dioxide. It is likely that at higher heating rates the increase in the partial pressure of carbon dioxide close to the surface, and within, the hydromagnesite particles is greater than at lower heating rates when the gas has more time to disperse. Therefore at higher heating rates crystallisation of magnesium carbonate is stronger due to the higher local partial pressure of the self generated carbon dioxide atmosphere. The sudden mass loss at $520^{\circ} \mathrm{C}$, clearly visible in Figure 11 , has been attributed[12] to 'explosive' release of carbon dioxide trapped within the hydromagnesite particles. Thermal energy due the mechanical stress caused by entrapped carbon dioxide and its explosive release has also been suggested as a cause for the exotherm. However the appearance of a second stage of mass loss above $520^{\circ} \mathrm{C}$ suggests that a combination of the two mechanisms is likely.

At slow heating rates hydromagnesite initially releases water of crystallisation followed by decomposition of the hydroxide ion releasing further water. The remaining magnesium carbonate decomposes directly to magnesium oxide by releasing carbon dioxide.

At high heating rates the release of water of crystallisation and decomposition of the hydroxide ion follows the same mechanism as it does at slower heating rates. The remaining magnesium carbonate begins to decompose releasing carbon dioxide. Because the heating rate is high the pressure of carbon dioxide within the hydromagnesite particles increases, as does the partial pressure of the gas at the particle surfaces. This causes an increasing amount of the carbonate ions to remain intact within the crystal structure until a critical temperature of $520^{\circ} \mathrm{C}$ is reached. At this temperature the remaining magnesium carbonate exothermically recrystallises to form a more thermally stable structure. The shift in the atomic arrangement of the magnesium carbonate releases any entrapped carbon dioxide leading to a sudden mass loss at the recrystallisation temperature. The higher the rate of heating the more pronounced this effect becomes.

\subsection{Thermal decomposition of a mixture of huntite and hydromagnesite}

Huntite and hydromagnesite extracted from Turkey occurs as a natural mixture of the two minerals, and in its use as a fire retardant it is also used as a mixture. Figure 13 shows how the minerals influence each other when mixed together. The thermal decomposition of the two individual minerals was measured using TGA, along with a manually created equal mass mixture. The manually created 
mixture of the two minerals was used to ensure this mixture was directly comparable to the individual huntite and hydromagnesite components. The expected mass loss profile of the mixture of the minerals was calculated by proportionally summing the measured mass loss profiles of the individual minerals.

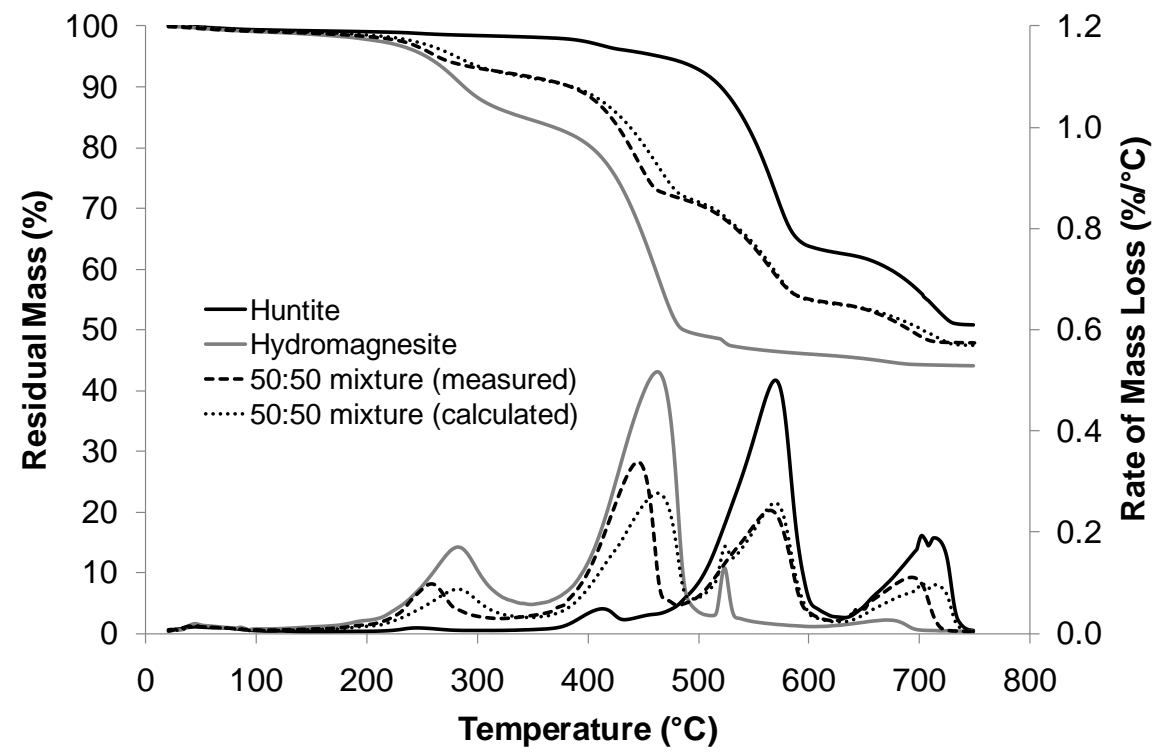

Figure 13: Measured and calculated thermal decomposition of a mixture of huntite and hydromagnesite by TGA

The measured mass loss of the mixture corresponds closely to that of the calculated mass loss profile. Both show decomposition taking place through four stages of mass loss and the mass losses for each stage correspond well with each other. Therefore the decomposition mechanism of the mixture is unaffected by the presence of the other mineral. However, each stage of the measured decomposition occurs at a lower temperature than calculated.

The thermal decomposition of hydromagnesite, when measured alone, will have generated a larger endotherm per gram of material present at any specific temperature than when mixed with huntite this may have slowed the decomposition of hydromagnesite when measured alone. In the mixture over most of the temperature range at which hydromagnesite decomposes the huntite is inert, therefore there is less overall cooling in the mixture than in the sample of hydromagnesite alone. This means the mixture will heat more readily than the individual minerals. The effect will be less significant over the temperature range at which huntite decomposes because the hydromagnesite will have decomposed meaning the dilution effect on the huntite portion of the mixture is smaller than it is on the hydromagnesite. This is seen in the difference between measured and calculated decomposition being less for the huntite portion of the mixture than for the hydromagnesite portion.

The calculated rate of mass loss shows that the drop at $520^{\circ} \mathrm{C}$ associated with the decomposition of crystallised magnesium carbonate formed from the hydromagnesite should be detected in the mixture. However, the measured decomposition of the mixture did not show this. In the mixture the hydromagnesite particles are less closely packed due to the presence of huntite particles. Therefore, the partial pressure of carbon dioxide generated from the decomposition of hydromagnesite will be lower in the mixed sample than in the sample of hydromagnesite. It has been shown[13,16] that a higher partial pressure of carbon dioxide causes a higher degree of crystallisation. In a mixture of huntite and hydromagnesite crystallisation is less likely and therefore the predicted mass loss does not occur when the thermal decomposition is measured. As the heating rate is increased 
crystallisation is more likely to occur (see Figure 11), but is less than predicted from a mixture of the two minerals.

Figure 14 summarises the decomposition mechanisms discussed above, in relation to the decomposition of UltraCarb; a commercially available natural mixture of hydromagnesite and huntite. The data shown in Figure 14 was measured at a heating rate of $10^{\circ} \mathrm{C} \mathrm{min}{ }^{-1}$. At this heating rate only a minimal amount of crystallisation of magnesium carbonate is expected to occur during the decomposition.

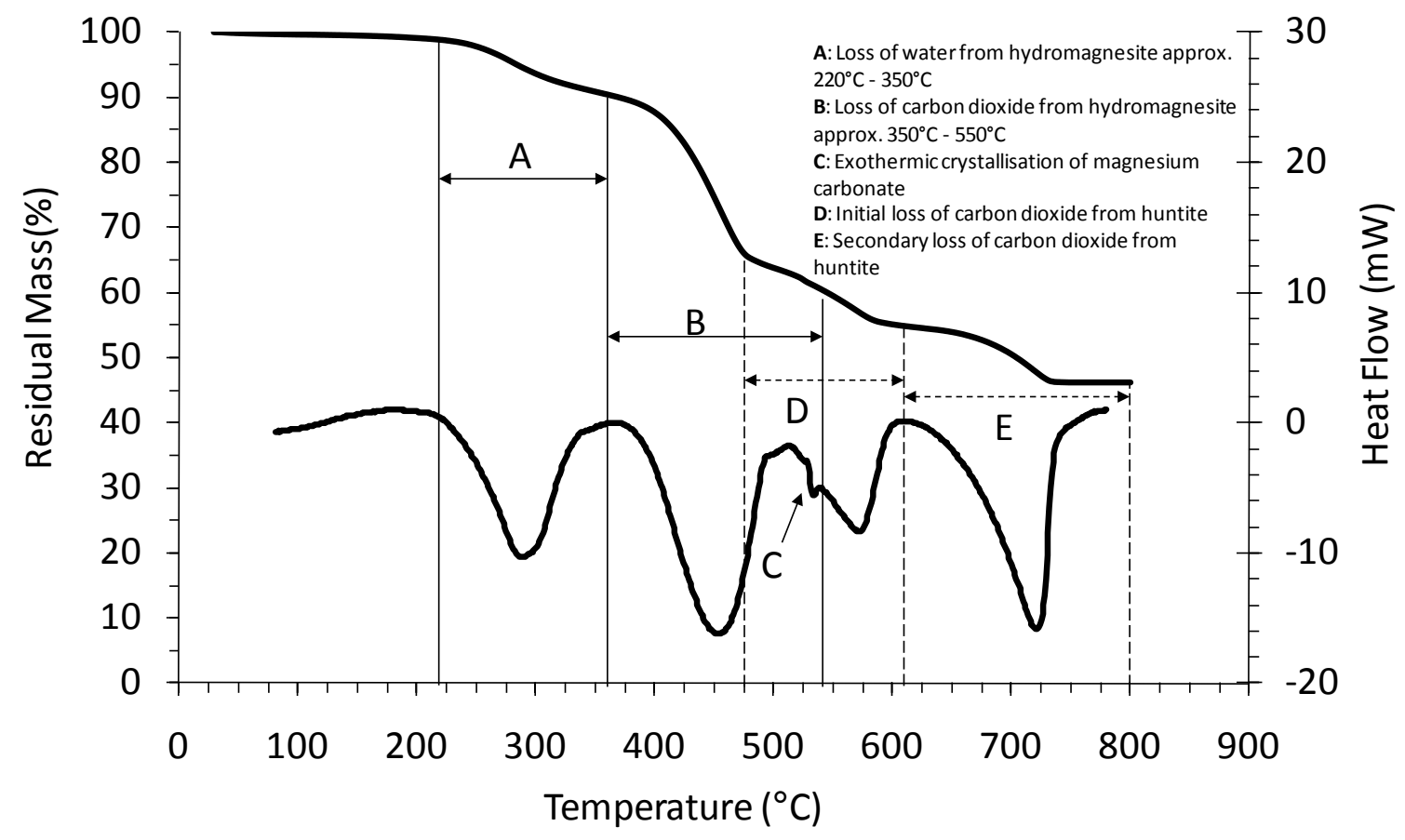

Figure 14: TGA and DSC decomposition of natural mixture of hydromagnesite and huntite (UltraCarb LH15)

An initial mass loss and associated endotherm (A) between the temperatures of $220^{\circ} \mathrm{C}$ and $350^{\circ} \mathrm{C}$ is due to the loss of crystalline water from the hydromagnesite. This is followed by a second step in mass loss. In Figure 1 it is clear that this mass loss, associated with the loss of carbon dioxide from the hydromagnesite, is not complete until about $540^{\circ} \mathrm{C}(\mathrm{B})$. Therefore, it overlaps with the initial mass loss associated with loss of carbon dioxide from the huntite (D). The loss of the hydroxyl group from hydromagnesite as water is not detected as a separate mass loss in Figure 14. However, it was reported by Haurie[33] that this loss of water occurs between $380^{\circ} \mathrm{C}$ and $450^{\circ} \mathrm{C}$ which would mean that it occurs in the lower half of region $B$ in Figure 14. This region also covers the temperature range where carbon dioxide is being lost from the hydromagnesite. At about $520^{\circ} \mathrm{C}$ a slight discontinuity is seen in the DSC data (C). This is the temperature at which the exothermic crystallisation of magnesium carbonate has been reported. The heating rate used for this measurement was $10^{\circ} \mathrm{C} \mathrm{min}^{-1}$ which is why the exotherm is very small, indicating that there is only very minimal crystallisation of magnesium carbonate. It also occurs in the temperature range (D) at which huntite is endothermically decomposing. Figure 1 shows that above $520^{\circ} \mathrm{C}$ there is a continued slow loss in mass from hydromagnesite up to about $700^{\circ} \mathrm{C}$ which is probably slow degradation of the small amount of crystalline magnesium carbonate. 
Figure 1 shows that huntite begins to decompose rapidly at about $470^{\circ} \mathrm{C}$. This loss in mass with its associated endotherm is complete at about $610^{\circ} \mathrm{C}$. The decomposition over this temperature range (D) is due to the loss of carbon dioxide from the carbonate groups associated with the magnesium ions. A final mass loss and endotherm (E) between $610^{\circ} \mathrm{C}$ and $800^{\circ} \mathrm{C}$ is due to a final loss of carbon dioxide resulting from the decomposition of the carbonate groups associated with the calcium ions.

At $800^{\circ} \mathrm{C}$ the hydromagnesite has decomposed to leave a magnesium oxide residue and the huntite has decomposed to leave a mixture of calcium oxide and magnesium oxide.

\section{Conclusions}

Both huntite and hydromagnesite endothermically decompose releasing a mixture of water and carbon dioxide over a temperature range up to about $750^{\circ} \mathrm{C}$.

Hydromagnesite releases about $15 \%$ of its mass as water below about $350^{\circ} \mathrm{C}$, this corresponds to the mass loss expected from the loss of the four molecules of water of crystallisation. A further mass loss of $41 \%$ between about $350^{\circ} \mathrm{C}$ and $700^{\circ} \mathrm{C}$ corresponds to the mass loss expected from the decomposition of the hydroxide and carbonate ions. FTIR analysis of the evolved gases and comparison with the decomposition of magnesium carbonate and magnesium hydroxide confirms this as the probable decomposition mechanism. The decomposition of the carbonate ions is highly dependent on the heating rate. Higher heating rates cause an increase in the local partial pressure of carbon dioxide which in turn causes the partially decomposed hydromagnesite to recrystallise forming a structure which decomposes at a higher temperature.

Huntite thermally decomposes in two stages, releasing $50 \%$ of its original mass as carbon dioxide. Comparison with the thermal decomposition of magnesium carbonate and calcium carbonate suggests that when huntite decomposes it initially loses carbon dioxide from the carbonate ions associated with the magnesium ions, followed by decomposition of the carbonate ion associated with the calcium ion.

Since both minerals decompose endothermically and release non-combustible gases mixtures of the two have great potential to act as fire retardant fillers in polymer materials. The higher onset of decomposition temperature of natural hydromagnesite compared to its synthetic version is a significant advantage in terms of polymer processing. 


\section{References}

1. Hollingbery LA, Hull TR. The Thermal Decomposition of Huntite and Hydromagnesite - A Review. Thermochim. Acta. 2010;509:1-11

2. Hull TR, Witkowski A, Hollingbery LA. Fire retardant action of mineral fillers. Polym. Degrad. Stab.. 2011;96:1462-1469

3. Beck CW. Differential Thermal Analysis Curves of Carbonate Minerals. Am. Mineral.. 1950;35:9851013

4. Faust GT. Huntite, A New Mineral. Am. Mineral.. 1953;38:4-24

5. Kangal O, Güney A. A new industrial mineral: Huntite and its recovery. Miner. Eng.. 2006;19:376378

6. Ozao R, Otsuka R. Thermoanalytical investigation of huntite. Thermochim. Acta. 1985;86:45-58

7. Bariand $\mathrm{P}$, Cesbron FP, Vachey $\mathrm{H}$, Sadrzadeh M. Hydromagnesite from Soghan, Iran. The Mineralogical Record. 1973;4:18-20

8. Botha A, Strydom C. DTA and FT-IR analysis of the rehydration of basic magnesium carbonate. J. Therm. Anal. Calorim. 2003;71:987-996

9. Frost RL, Hales MC, Locke AJ, Kristof J. Controlled Rate Thermal Analysis of Hydromagnesite. J. Therm. Anal. Calorim. 2008;92:893-897

10. Haurie L, Fernandez AI, Velasco JI, Chimenos JM, Lopez-Cuesta JM, Espiell F. Effects of milling on the thermal stability of synthetic hydromagnesite. Mater. Res. Bull. 2007;42:1010-1018

11. Inglethorpe SDJ, Stamatakis MG. Thermal decomposition of natural mixtures of hydromagnesite and huntite from Kozani, Northern Greece. Mineral Wealth. 2003:7-18

12. Khan N, Dollimore D, Alexander K, Wilburn FW. The origin of the exothermic peak in the thermal decomposition of basic magnesium carbonate. Thermochim. Acta. 2001;367-368:321-333

13. Padeste C, Oswald HR, Reller A. The thermal behaviour of pure and nickel-doped hydromagnesite in different atmospheres. Mater. Res. Bull. 1991;26:1263-1268

14. Rajeswara R, Chohan VS. Kinetics of Thermal Decomposition of Hydromagnesite. Chem. Eng. Technol. 1995;18:359-363

15. Sawada $\mathrm{Y}$, Uematsu K, Mizutani N, Kato M. Thermal decomposition of hydromagnesite $4 \mathrm{MgCO}_{3} \cdot \mathrm{Mg}(\mathrm{OH})_{2} \cdot 4 \mathrm{H}_{2} \mathrm{O}$. J. Inorg. Nucl. Chem. 1978;40:979-982

16. Sawada $\mathrm{Y}$, Uematsu $\mathrm{K}$, Mizutani $\mathrm{N}$, Kato $\mathrm{M}$. Thermal decomposition of hydromagnesite $4 \mathrm{MgCO}_{3} \cdot \mathrm{Mg}(\mathrm{OH})_{2} \cdot 4 \mathrm{H}_{2} \mathrm{O}$ under different partial pressures of carbon dioxide. Thermochim. Acta. 1978;27:45-59

17. Sawada Y, Yamaguchi J, Sakurai O, Uematsu K, Mizutani N, Kato M. Thermal decomposition of basic magnesium carbonates under high-pressure gas atmoshpheres. Thermochim. Acta. 1979;32:277-291

18. Sawada Y, Yamaguchi J, Sakurai O, Uematsu K, Mizutani N, Kato M. Thermogravimetric study on the decomposition of hydromagnesite $4 \mathrm{MgCO}_{3} \cdot \mathrm{Mg}(\mathrm{OH})_{2} \cdot 4 \mathrm{H}_{2} \mathrm{O}$. Thermochim. Acta. 1979;33:127-140 
19. Sawada Y, Yamaguchi J, Sakurai O, Uematsu K, Mizutani N, Kato M. Isothermal differential scanning calorimetry on an exothermic phenomenon during thermal decomposition of hydromagnesite $4 \mathrm{MgCO}_{3} \cdot \mathrm{Mg}(\mathrm{OH})_{2} \cdot 4 \mathrm{H}_{2} \mathrm{O}$. Thermochim. Acta. 1979;34:233-237

20. Anthony JW, Bideaux RA, Bladh KW, Nichols MC. Handbook of Mineralogy. http://www.handbookofmineralogy.org/pdfs/hydromagnesite.pdf, accessed 14/04/2009

21. Anthony JW, Bideaux RA, Bladh KW, Nichols MC. Handbook of Mineralogy. http://www.handbookofmineralogy.org/pdfs/huntite.pdf, accessed 14/04/2009

22. Hollingbery LA, Hull TR. The fire retardant behaviour of huntite and hydromagnesite - A review. Polym. Degrad. Stab.. 2010;95:2213-2235

23. Basfar AA, Bae HJ. Influence of Magnesium Hydroxide and Huntite Hydromagnesite on Mechanical Properties of Ethylene Vinyl Acetate Compounds Cross-linked by DiCumyl Peroxide and Ionizing Radiation. J. Fire Sci. 2010;28:161-180

24. Bolger R. Flame retardant minerals bromine issue smoulders on. Industrial Minerals. 1996:29-39

25. Briggs C, Rutherford A, SPE. Unique Flame Retardant Filler for Pe and Other Cable Compounds. Proceedings Antec '90, Dallas, 1990:1216-1221

26. Briggs CC. Reduced Hazard Flame Retardant PVC Compounds. Proceedings PVC '93, Brighton, 1993

27. Briggs CC. Ultracarb: The natural flame retardant. Paper presented at the Fillers and Additives in Plastics '91 European Technical Conference, held 9-10 October, 1991, Lund, Sweden. 1991:20

28. Briggs CC, Bhardwaj B, Gilbert M. Flame Retardant PVC Cable Compounds using HuntiteHydromagnesite. Proceedings Filplas '92, Manchester. 1992

29. Briggs CC, Day RC, Gilbert M, Hollingbery LA. Optimising Fire Properties for Plasticised PVC Compounds. Proceedings PVC '96, Brighton. 1996:269-280

30. Briggs CC, Hollingbery LA, Day RC, Gilbert M. Optimising fire properties of plasticised poly(vinyl chloride) compounds. Plast. Rubber Compos. Process. Appl. 1997;26:66-77

31. Clemens ML, Doyle MD, Lees GC, Briggs CC, Day RC. Non-Halogenated Flame Retardant for Polypropylene. Proceedings: Flame Retardants '94, Manchester. 1994:193-202

32. Haurie L, Fernández Al, Velasco JI, Chimenos JM, Lopez Cuesta J, Espiell F. Thermal stability and flame retardancy of LDPE/EVA blends filled with synthetic hydromagnesite/aluminium hydroxide/montmorillonite and magnesium hydroxide/aluminium hydroxide/montmorillonite mixtures. Polym. Degrad. Stab.. 2007;92:1082-1087

33. Haurie L, Fernández Al, Velasco JI, Chimenos JM, Lopez Cuesta J, Espiell F. Synthetic hydromagnesite as flame retardant. Evaluation of the flame behaviour in a polyethylene matrix. Polym. Degrad. Stab.. 2006;91:989-994

34. Haurie L, Fernández Al, Velasco Jl, Chimenos JM, Ticó-Grau JR, Espiell F. Synthetic Hydromagnesite as Flame Retardant. A Study of the Stearic Coating Process. Macromol. Symp. 2005;221:165-174

35. Kandola BK, Pornwannachai W. Enhancement of Passive Fire Protection Ability of Inorganic Fire Retardants in Vinyl Ester Resin Using Glass Frit Synergists. J. Fire Sci. 2010;28:357-381 
36. Kirschbaum GS. Huntite/hydromagnesite - Mineral Flame Retardants as Alternative and Complement to Metal Hydroxides. Proceedings: Flame Retardants '98, London. 1998:151-161

37. Kirschbaum G. Minerals on Fire: Flame Retardants Look to Mineral Solutions. Industrial Minerals. 2001:61-67

38. Laoutid F, Gaudon P, Taulemesse J-, Lopez Cuesta JM, Velasco JI, Piechaczyk A. Study of hydromagnesite and magnesium hydroxide based fire retardant systems for ethylene-vinyl acetate containing organo-modified montmorillonite. Polym. Degrad. Stab.. 2006;91:3074-3082

39. Morgan AB, Cogen JM, Opperman RS, Harris JD. The effectiveness of magnesium carbonatebased flame retardants for poly(ethylene-co-vinyl acetate) and poly(ethylene-co-ethyl acrylate). Fire and Materials. 2007;31:387-410

40. Rigolo M, Woodhams RT. Basic magnesium carbonate flame retardants for polypropylene. Polym. Eng. Sci. 1992;32:327-334

41. Toure B, Cuesta JL, Gaudon P, Benhassaine A, Crespy A. Fire resistance and mechanical properties of a huntite/hydromagnesite/antimony trioxide/decabromodiphenyl oxide filled PP-PE copolymer. Polym. Degrad. Stab.. 1996;53:371-379

42. Touré B, Lopez-Cuesta J, Benhassaine A, Crespy A. The Combined Action of Huntite and Hydromagnesite for Reducing Flammability of an Ethylene-Propylene Copolymer. Int. J. Polym. Anal. Charact. 1996;2:193-202

43. Bensalem A, Chang W, Fournier A, Kallianos G, Paine J, Podraza K, Schleich D, Seeman J. Smoking Article Wrapper Having Filler of Hydromagnesite / Magnesium Hydroxide and Smoking Article made with said Wrapper. US Patent 5,979,461. 1999

44. Bensalem A, Chang W, Fournier JA, Kallianos AG, Paine J, Podraza K, Schleich D, Seeman J. Hydromagnesite / Magnesium Hydroxide Fillers for Smoking Article Wrappers and Methods for making Same. US Patent 5,927,288. 1999

45. Liodakis S, Agiovlasitis IP, Antonopoulos I, Stamatakis MG. Fire retarding performance of hydromagnesite on forest species from a wildland/urban interface area in Athens. For. Ecol. Manage. 2006;234:S126-S126

46. Liodakis S, Antonopoulos I. Evaluating the fire retardation efficiency of diammonium phosphate, ammonium sulphate and magnesium carbonate minerals on Pistacia lentiscus L. Environment Identities and Mediterranean Area, 2006 ISEIMA '06 First international Symposium on. 2006:35-39

47. Liodakis S, Antonopoulos I, Agiovlasitis IP, Kakardakis T. Testing the fire retardancy of Greek minerals hydromagnesite and huntite on WUI forest species Phillyrea latifolia L. Thermochim. Acta. 2008;469:43-51

48. Liodakis S, Antonopoulos I, Kakardakis T. Evaluating the use of minerals as forest fire retardants. Fire Saf. J. 2010;45:98-105

49. Liodakis S, Antonopoulos I, Tsapara V. Forest fire retardancy evaluation of carbonate minerals using DTG and LOI. J. Therm. Anal. Calorim. . 2009;96:203-209

50. Graf DL, Bradley WF. The crystal structure of huntite, $\mathrm{Mg}_{3} \mathrm{Ca}\left(\mathrm{CO}_{3}\right)_{4}$. Acta Crystallogr. $1962 ; 15: 238-242$

51. Akao M, Iwai S. The hydrogen bonding of hydromagnesite. Acta Crystallogr. Sect. B. 1977;33:1273-1275 
52. Akao M, Maruma F, Iwai S. The crystal structure of hydromagnesite. Acta Crystallogr. Sect. B. 1974;30:2670-2672

53. Murdoch J. Unit Cell of Hydromagnesite. Am. Mineral.. 1954;39:24-29

54. Xiong Y. Experimental determination of solubility constant of hydromagnesite (5424) in $\mathrm{NaCl}$ solutions up to $4.4 \mathrm{~m}$ at room temperature. Chem. Geol. 2011;284:262-269 